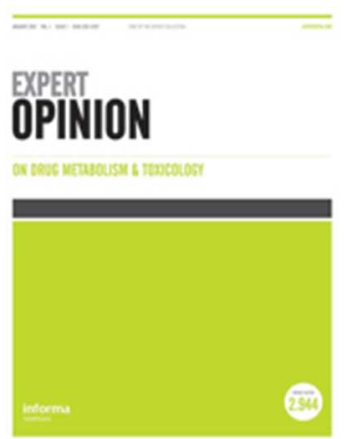

Please download and read the Referee Guidelines

\title{
Alleviation of pain in painful diabetic neuropathy
}

\begin{tabular}{|r|l|}
\hline Journal: & Expert Opinion On Drug Metabolism and Toxicology \\
\hline Manuscript ID & EOMT-2016-0021.R1 \\
\hline Manuscript Type: & Review \\
\hline Keywords: & $\begin{array}{l}\text { antidepressants, antiepileptics, diabetes, metabolism, painful neuropathy, } \\
\text { pharmacodynamics, pharmacokinetics, treatment }\end{array}$ \\
\hline
\end{tabular}

SCHOLARONE ${ }^{m}$

Manuscripts 
1

2

3

4

5

6

7

8

9

10

11

12

13

14

15

16

17

18

19

20

21

22

23

24

25

26

27

28

29

30

31

32

33

34

35

36

37

38

39

40

41

42

43

44

45

46

47

48

49

50

51

52

53

54

55

56

57

58

59

60

Alleviation of pain in painful diabetic neuropathy 


\section{Abstract}

Introduction: Painful diabetic neuropathy (PDN) is a disabling pain condition. Its pathomechanism remains unknown, but a sensitization and neuronal hyperexcitabilty have been suggested. Only symptomatic pharmacological pain-alleviation treatment is currently available.

Areas covered: The origin of PDN is enigmatic, and the evidence-based therapeutic guidelines therefore consist only of antidepressants and antiepileptics as first-line recommended drugs. This article relates to a MEDLINE/PubMed systematic search (20052015).

Expert opinion: The results of the meta-analysis from the aspect of the efficacy of amitriptyline, duloxetine, venlafaxine, gabapentin and pregabalin are favorable, but the placebo response rate is relatively high in patients with neuropathic pain. For personalization of the medication of PDN patients, the optimum dosing, the genotyping of the metabolizing enzymes and optimum biomarkers are needed. As concerns the future perspectives, specific sodium channel subtype inhibitors acting on peripheral nociceptive neurons or modified Ttype voltage-gated calcium channel blockers may be promising targets for pharmaceutical innovations. Another attractive strategy for the treatment is based on the effects of monoclonal antibodies against nerve growth factor, sodium channel, specific receptor and cytokines. Botulinum toxin A, capsaicin patch and spinal cord stimulation therapies are the nearest future therapeutic options for the treatment of PDN patients.

Keywords: antidepressants, antiepileptics, diabetes, metabolism, painful neuropathy, pharmacodynamics, pharmacokinetics, treatment 


\section{Article highlights}

- The pathomechanism of painful diabetic neuropathy is unknown, and therefore only symptomatic non-specific treatment is available.

- As a tricyclic antidepressant, amitriptyline has multimodal action, and is effective with a favorable number needed to treat, but it exerts many unfavorable adverse events related to its pharmacological profile.

- The selective serotonin-norepinephrine reuptake inhibitor duloxetine has been subjected to pharmacogenomic studies.

- Venlafaxine has a strong dose-dependent effect and due to its extended release formulation, the treatment-related adverse events are low.

- Gabapentin as an antiepileptic has no metabolism and no drug-drug interactions with a high adherence level.

- Pregabalin as a gabapentinoid with linear kinetics has been strongly recommended for the treatment of painful diabetic neuropathy. 


\section{Introduction}

Neuropathic pain (NP), one of the most devastating pain conditions by definition caused by a lesion or disease of the somatosensory system ${ }^{[1]}$. It has distinct clinical features with a heterogeneity of different causes ${ }^{[2,3]}$. Neuropathic sensory symptoms characterized by spontaneous or evoked pain is described as electric shock-like or burning, and other sensory disturbances such as paraesthesia, dysaesthesia, allodynia, hyperpathia or hyperalgesia. The symptoms of painful diabetic neuropathy (PDN) occur symmetrically in the distal parts of the extremities in an ascending manner ${ }^{[4,5]}$. The aetiology of NP involves a wide range of peripheral or central nervous system (CNS) disorders, including diabetic and other metabolic neuropathies, dysimmune neuropathies, postherpetic neuralgia, trigeminal neuralgia, human immundeficiency virus (HIV)-associated neuropathy or pain after spinal cord injury, poststroke pain, multiple sclerosis-associated pain or cancer-related pain ${ }^{[5]}$.

Diabetes mellitus is a modern global medical challenge with an estimated prevalence of 366 million patients in $2030^{[6]}$. Recent epidemiological data showed that the estimated presence of NP was around $7 \%$ of the general population in Europe ${ }^{[7]}$. Diabetic neuropathy ocurs in $59-66 \%$ of insulin-dependent (type 1) and non-insulin-dependent (type 2) diabetic patients ${ }^{[8]}$. The adjusted incidence of diabetic polyneuropathy is 54 per 100,000 persons per year ${ }^{[9]}$. Several studies have reported a prevalence of PDN of $10.9-20.0 \%{ }^{[10]}$. Diabetic neuropathy and pain occur more frequently in type 2 diabetes mellitus, in women and in non-Caucasians [6].

The personal and socio-economic impact of PDN is high, influencing the quality of life, the work productivity and the functional disability of the patients ${ }^{[11]}$. The total annual direct medical costs for PDN were recently estimated as 27,931 USD and for severe PDN as 30,755 $\mathrm{USD}^{[11]}$. PDN has a significant impact on the health-related quality of life ${ }^{[12]}$.

The pathomechanism of NP has not yet been completely clarified, but the sensitization process is widely accepted as playing an important role. Hyperexcitability and sensitization in NP similar to migraine as a primary headache disorder involve changes in the peripheral nervous system and $\mathrm{CNS}^{[5,13-16]}$. One of the key elements of the peripheral sensitization is the increased expression of voltage-gated sodium channels $\mathrm{Na}_{\mathrm{v}} 1.8$ and $\mathrm{Na}_{\mathrm{v}} 1.9$ on lesioned peripheral nerves, which are the sources of ectopic pain impulse generation. The upregulation of sodium ion channels is a consequence of nerve growth factor (NGF) release from the damaged peripheral sensory nerve fibres ${ }^{[17]}$. NGF is the first discovered member of the neurotrophin family. Other members of this family include brain-derived neurotrophic factor (BDNF), neurotrophin-3 (NT-3), and neurotrophin-4/5 (NT-4/5) ${ }^{[18]}$. The receptors 
of these molecules belong to the tropomysin receptor kinase (Trk) family. NGF binds to TrkA with high affinity, whereas BDNF and NT-4 bind to TrkB, and NT-3 binds to TrkC ${ }^{[19]}$. These molecules have a common Trk downstream pathway involved in the induction of neuropathic pain ${ }^{[19]}$. Recent clinical findings have shown that anti-NGF antibody and small molecule TrkA inhibitors alleviate neuropathic pain ${ }^{[18,19]}$.

Ectopic primary afferent firing clinically explains the devastating spontaneous burning pain and unpleasant electric shock-like sensations ${ }^{[20]}$. Another important mechanism of the peripheral sensitization is the presence of the proinflammatory cytokines, bradykinin, prostaglandins, 5-hydroxytryptamine and histamine ('inflammatory soup') along the damaged peripheral nerve elements from the dorsal root ganglion (DRG) to the nociceptors in the target tissue ${ }^{[17,20-23]}$. Human genetic studies revealed the important role of Nav1.7 in pain sensation ${ }^{[24]}$. Nav1.7 is expressed in small-sized nociceptive DRG neurons ${ }^{[25]}$ and takes part in spinal cord nociceptive synaptic transmission involved in neuropathic pain processing ${ }^{[26,27]}$. The importance of Nav1.7 is also highlighted by the findings that its expression level was found increased in DRG neurons in diabetic rats ${ }^{[28,29]}$.

Recent findings demonstrate the importance of the microglia function in the central sensitization process. The central terminals of the damaged primary sensory neurons in the spinal cord release adenosine triphosphate (ATP), which is able to activate the microglia via purinergic $(\mathrm{P} 2 \mathrm{X} 4)$ receptors. The activated microglia releases the BDNF, which activates the TrkB receptors, resulting in the down-regulation of the $\mathrm{K}^{+}-\mathrm{Cl}^{-}$cotransporter 2 of the nociceptive second-order neurons in spinal lamina I. These nerve cells convey the information to the thalamus (the third-order neurons) and project to the somatosensory cortex ${ }^{[21,30]}$. Excitatory amino acids, mainly glutamate and its receptors (N-methyl-D-aspartate (NMDA) receptors), have also been implicated in the pathomechanism of the NP ${ }^{[31]}$. The membrane depolarization caused by nociceptive stimuli permits NMDA receptor-mediated synaptic transmission. Calcium influx into the cells activates the non-receptor tyrosine kinase, which leads to phosphorylation of the NMDA receptors ${ }^{[31]}$. This process leads to the glutamaterelated hypersensitivity of the neuronal cells ${ }^{[31]}$ (Figure 1).

PDN is an underdiagnosed and an undertreated condition in the daily clinical practice ${ }^{[4]}$. The aim of this article is to give an overview of the current evidence-based symptomatic treatment of PDN, focusing on the metabolism and toxicological properties of the strongly recommended first-line drugs (antidepressants and antiepileptics) in order to promote good clinical practice ${ }^{[3,6,32]}$. We also provide data on future therapeutic options (i.e. neutrophins, NO-donors, sodium channel blockers, monoclonal antibodies (mAb) 
against Nav1.7, integrins and NGF, botulinum toxin type A, topical capsaicin patch, TRPV1 and TRPA1 antagonists, and neuromodulation approaches), and give an outlook toward personalized medicine. The realization of drug-drug and drug-gene interactions (i.e. observed or inferred interactions between gene products and drug compounds) are fundamental elements of novel pharmaceutical innovation and modern therapeutic approaches forPDN patients ${ }^{[33]}$.

\section{Symptomatic pain treatment of PDN}

The exact pathomechanism of the origin of the pain, associated with diabetic neuropathy is still lacking, and specific pharmacons for NP do not exist. The currently used drugs for NP were originally developed for depression, epilepsy and cancer-related pain, but they are effective at different levels in the alleviation of NP. This type of therapy is considered to be successful in achieving at least a $50 \%$ pain intensity reduction ${ }^{[34]}$. In this field, it is an important fact that the placebo effect for NP is higher than those for other disorders ${ }^{[4]}$.

Over recent decades, several therapeutic recommendations and guidelines for NP and PDN have been put forward ${ }^{[6,35,36]}$. The recent evidence-based recommendations for the oral and topical pharmacotherapy of NP were published by the Neuropathic Pain Special Interest Group (NeuPSIG) of the International Association for the Study of Pain ${ }^{[3,7]}$. The guideline of NeuPSIG used the Grading of Recommendation Assessment, Development and Evaluation (GRADE) system, which is based on the consensus on the rating of the quality of evidence and strength of recommendations ranging from weak to strong for or against the treatment ${ }^{[3,7}$, 37].

This current survey analyses the pharmacological (pharmacokinetic and pharmacodynamic) and toxicological properties (absorption, distribution, metabolism and excretion) of the firstline (strong recommendation) drugs for PDN suggested by the NeuPSIG recommendations.

\subsection{Antidepressants}

From the aspect of the efficacious treatment of PDN, among the antidepressive drugs tricyclic antidepressants (TCAs) and serotonin-norepinephrine reuptake inhibitors (SNRIs) are beneficial. Their analgesic effect is independent of their antidepressant properties ${ }^{[7]}$.

\subsubsection{Tricyclic antidepressants (TCAs)}


The group of TCAs involves amitriptyline (AMI), clomipramine, desipramine, imipramine and nortryptiline. TCAs generally have similar efficacy as concerns PDN ${ }^{[3]}$. Particularly AMI has been investigated in most clinical trials for PDN ${ }^{[6]}$.

\subsubsection{Amitriptyline (AMI)}

AMI is a more than 50-year-old drug, which was approved for the indication of depression by the US Food and Drug Administration (FDA) in 1961, and is still in use for the treatment of PDN world-wide ${ }^{[38]}$.

The chemical structure of AMI is 3-(10,11-dihydro-5H-dibenzo[a,d]cycloheptene-5-ylidene)$N, N$-dimethylpropan-1-amine (Figure 2).

The mode of action of AMI is the inhibition of the re-uptake of norepinephrine and serotonin at the adrenergic nerve endings in the synaptic cleft ${ }^{[39]}$. It has multimodal actions such as an anticholinergic effect, histaminergic down-regulation, gamma-aminobutyric acid (GABA)-B receptor up-regulation, $\alpha$-adrenergic receptor antagonism and sodium, L-type calcium and Kv1.1, Kv7.2, and Kv7.3 voltage-gated potassium ion channel blockade ${ }^{[34,40,41]}$. Importantly, AMI is an agonist of the TrkA and TRkB receptors, so it influences the activation of the NGF and $\mathrm{BDNF}^{[42]}$. It enhances the neuronal sensitivity to substance $\mathrm{P}$, but does not inhibit the reuptake of dopamine or monoamine oxidase ${ }^{[39]}$. AMI increases the activation of the adenosine A1 receptor, which leads to antinociception ${ }^{[40]}$.

The pharmacokinetic parameters of $75 \mathrm{mg}$ of an orally administered osmotic controlled release tablet of AMI revealed that the maximum plasma concentration $\left(\mathrm{C}_{\max }\right)$ was $15.3( \pm 7.0$ standard deviation, S.D.) ng/L, the area under the concentration vs. time curve (AUC) was 593 ( \pm 229 S.D.) $n g / m L x ~ h$, the time to $\mathrm{C}_{\max }\left(\mathrm{T}_{\max }\right)$ was $25.7( \pm 5.8$ S.D.) $\mathrm{h}$ and the plasma elimination half-life $\left(\mathrm{T}_{1 / 2}\right)$ was $20.4( \pm 4.3$ S.D. $) \mathrm{h}^{[39]}$. The bioavailability of AMI is $30-60 \%$, the protein binding is $96 \%$. Its active metabolite is nortryptyline ${ }^{[43]}$. It is metabolized on the first pass through the liver by cytochrome P450 (CYP450) isoenzymes (CYP2C19 and CYP2D6) and is excreted renally (around 30-50\%) $\left(\right.$ Table 1) ${ }^{[39]}$.

As regards the pharmacogenetic aspects of AMI, the risk of the lack of efficacy or the occurrence of side-effects depends on the types of metabolizer (poor, intermediate, extensive or ultrarapid), and the genetic variations of CYP2C19 or CYP2D6 enzymes. The Clinical Pharmacogenetics Implementation Consortium recommends therapeutic drug monitoring for the guided dose adjustment ${ }^{[44]}$. 
The results of clinical trials for managing PDN revealed a superior effect of AMI to placebo ${ }^{[45]}$. The number needed to treat (NNT) of AMI is 1.3 , which means an extremely good rank (Table 2) ${ }^{[34]}$. The recommended daily dose of AMI for PDN is $25-100 \mathrm{mg}^{[4]}$.

Due to its multimodal actions, AMI resulted in several unfavorable adverse events (AEs) regarding anticholinergic, histaminergic, adrenergic, dopamineric and serotoninergic effects ${ }^{[43]}$. The common ( $>1 \%$ frequency) AEs of AMI are dry mouth, fatigue, somnolence, weight gain and dizziness ${ }^{[7,46]}$. Contraindications for AMI use are a history of myocardial infarction, arrhythmias, heart block, congestive heart failure, coronary artery insufficiency and severe liver disease ${ }^{[47]}$. An increased risk of sudden cardiac death mainly occurs at a dosage of more than $100 \mathrm{mg}$ per day ${ }^{[3]}$. Caution is needed for AMI users with comorbidity, e.g. narrow angle glaucoma, urinary retention, prostatic hypertrophy, a history of epilepsy or hyperthyroidism ${ }^{[7}$, 47].

The Cochrane Database revealed that AMI was effective for the treatment of PDN, but its wide-range use was limited by its unfavorable safety and tolerability profile ${ }^{[48]}$. The NeuSPIG consensus declares that TCAs reached the strong recommendations for use in the treatment of $\mathrm{PDN}^{[3]}$.

\subsubsection{Serotonin-norepinephrine reuptake inhibitors (SNRIs)}

SNRIs have dual effects: they are strong blockers of the reuptake of serotonin and norepinephrine. The pharmacological group of SNRIs includes duloxetine (DUL), venlafaxine (VEN), desvenlafaxine, milnacipran, levomilnacipran and sibutramine. For the treatment of PDN, DUL and VEN have shown good efficacy ${ }^{[34]}$.

\subsubsection{Duloxetine (DUL)}

DUL was developed in 1988, and FDA approval for depression and PDN was dated in 2004 $[34,49]$. The chemical structure of DUL is $(+)-(S)-N$-methyl-3-(naphthalen-1-yloxy)-3(thiophen-2-yl) propan-1-amine. It is a potent and selective dual neuronal SNRI (serotonin:norepinephrine effects $10: 1)^{[50]}$. It is a weak inhibitor of dopamine transporters and does not have a strong effect on cholinergic, histaminergic, opioid, glutamate and GABA reuptake transporters ${ }^{[51-53]}$. It does not block the monoamine oxidase types A or $\mathrm{B}^{[53]}$. DUL has the capability to block the production and/or release of pro-inflammatory cytokines and/or can also provoke the production of anti-inflammatory cytokines ${ }^{[54]}$. DUL has properties for the modulation of nitroxidative stress by influencing the balance between pro-oxidant and anti-oxidant processes ${ }^{[55]}$. One of the basic modes of action of DUL in the alleviaton of pain 
in PDN is based on the blockade of the neuronal sodium ion channel ${ }^{[56]}$. DUL blocks persistent late Nav1.7 $\mathrm{Na}^{+}$currents preferentially, which may account in part for its analgesic action ${ }^{[56]}$. In a preclinical study it was shown that the impaired norepinephrine homeostasis is one of the major factors of the PDN model in rats, and the analgesic effect of DUL might be due to the enhancement of noradrenergic signals ${ }^{[57]}$.

The pharmacokinetic parameters of single oral dose of $60 \mathrm{mg}$ of DUL tablet revealed that $\mathrm{C}_{\max }$ was 39-40.1 ng/L, AUC was 584-591 $\mathrm{ng} \times \mathrm{h} / \mathrm{mL}, \mathrm{T}_{\max }$ was $6 \mathrm{~h}$ and $\mathrm{T}_{1 / 2}$ was $10.2 \mathrm{~h}^{[53 \text {, }}$ 58]. The bioavailability of DUL is $50 \%$, and the protein biding (mainly to albumin) is high $(>90 \%)$, and widely distributed throughout the tissues (the volume of distribution is approximately $1640 \mathrm{~L})^{[43,53,58]}$. The steady state of DUL is usually achieved by day 3 of administration ${ }^{[53]}$. Its circulating metabolites are pharmacologically inactive. It is metabolized by the liver (CYP1A2 and CYP2D6) and is excreted $70 \%$ in the urine and $20 \%$ in the faeces [43].

The pharmacokinetics of DUL is influenced by the demographic features of the patients, such as sex, smoking, age, ethnicity, hepatic and renal function ${ }^{[58]}$. The genotype of the CYP2D6 enzyme also influences the pharmacokinetics of DUL ${ }^{[58]}$. A recent pharmacogenomic study concluded that interleukin-6 variants (rs2066992 and rs10242595) may take part in DUL response in patients with major depression ${ }^{[59]}$. In DUL-treated patients with major depressive disorder, tests of the single-nucleotide polymorphisms demonstrated that variants in corticotropin-releasing hormone receptor 1 were associated with the DUL response ${ }^{[60]}$.

As concerns the drug-drug interactions of DUL, it should be underlined that activated charcoal diminishes DUL exposure and CYP1A2 blockade increases DUL exposure. In the presence of fluvoxamine, the AUC of DUL is increased more than $400 \%$ and Cmax is increased more than $100 \%{ }^{[58]}$. Smoking decreases the DUL plasma concentratin (by $\left.30 \%\right)^{[58]}$. In the presence of DUL with CYP2D6 inhibitors or in CYP2D6 poor metabolizers, the exposure of DUL is less increased as compared with CYP1A2 inhibition ${ }^{[58]}$. DUL has the capability to enhance the exposure of pharmacons that are metabolized by CYP2D6, but not CYP1A2 ${ }^{[58]}$. Pharmacodynamic trials suggested that DUL may enhance the effects of benzodiazepines, but not alcohol or warfarin ${ }^{[58]}$.

The investigation of the AmpliChip CYP450 Genotyping Test for genes CYP2D6 and CYP2C19 concluded that poor metabolizers accounted for around $7 \%$ of Caucasians for CYP2D6 and around 25\% of East Asians for CYP2C19, and ultra-rapid metabolizers for CYP2D6 of around 29\% in North Africa and the Middle-East ${ }^{[61,62]}$. 
The recent Cochrane Collaboration meta-analysis pointed out that $60 \mathrm{mg}$ and 120 daily doses of DUL were efficacious in the treatment of PDN ${ }^{[63]}$. The related NNT of benefit of DUL at $60 \mathrm{mg}$ is 5 (95\% confidential interval, CI 4 to 7 ) in the alleviation of pain in diabetic neuropathy ${ }^{[63]}$.

The recommended daily dose of DUL for PDN is $60-120 \mathrm{mg}$ once a day ${ }^{[3,4]}$.

Mild AEs of DUL were frequent at a high dose, such as nausea, dry mouth, headache, dizziness and fatigue ${ }^{[7,53,63]}$. The common AEs of DUL (60 mg per day) are somnolence $(20 \%)$ and constipation $(14 \%)^{[34,64]}$. Severe AEs of DUL were rare ${ }^{[63]}$. Precautions for the use of DUL are needed in cases of hepatic disorder, hypertension and concomitant medication with tramadol ${ }^{[7]}$.

The NeuSPIG consensus declared that DUL reached the strong recommendations for use in the treatment of PDN ${ }^{[3]}$.

\subsubsection{Venlafaxine (VEN)}

VEN was launched on the pharmaceutical market after FDA approval in 1993, and VEN extended release $(\mathrm{XR})$ in $1997^{[50]}$. Its chemical structure is $(R S)$-1-[2-dimethylamino-1-(4methoxyphenyl)ethyl]cyclohexanol.

VEN, as parent drug, and its active and structurally-similar major metabolite desvenlafaxine (O-desmethylvenlafaxine) are potent and selective dual neuronal SNRIs (VEN: serotonin:norepinephrine effects 30:1; desvenlafaxine: $10: 1)^{[50,65]}$. VEN has a strong dosedependent action: in low doses it inhibits serotonin reuptake, while in higher doses it blocks both serotonin and norepinephrine reuptake ${ }^{[66]}$. VEN and desvenlafaxine modulate the dopaminergic neurotransmission at low affinity level ${ }^{[50]}$. They may not influence the adrenergic, muscarinic, cholinergic, histaminergic, benzodiazepine or opioids receptors, or monoamine oxidase ${ }^{[65]}$. There are later data regarding the antinociceptive effect of VEN, which revealed that this analgetic effect may be influenced by opioid receptors and the alpha2-adrenergic receptor ${ }^{[67]}$. There are findings which proved that VEN XR can modify pituitary adenylate cyclase-activating peptide (PACAP) and its PAC1 receptor genes in generalized anxiety disorder ${ }^{[68]}$.

The pharmacokinetic parameters of orally administered VEN XR tablets of $150 \mathrm{mg}$ revealed that $\mathrm{C}_{\max }$ was $150 \mathrm{ug} / \mathrm{L}$, the AUC was $1877 \mathrm{ug} / \mathrm{L} \mathrm{x} \mathrm{h,} \mathrm{T}_{\max }$ was $5.5 \mathrm{~h}$ and $\mathrm{T}_{1 / 2}$ was $5 \mathrm{~h}^{[65]}$. The plasma protein binding of VEN XR at $150 \mathrm{mg}$ is $27 \%$ and its major metabolic pathway proceeds primarily through the liver by enzymes CYP2D6 and CYP3A3/4 ${ }^{[50]}$. It is mainly excreted in the urine $(87 \%)^{[65]}$. 
A recent Cochrane meta-analysis based on six randomized clinical trials showed a positive benefit for a daily dose of VEN above $150 \mathrm{mg}$ for the treatment of neuropathic pain (mostly PDN) ${ }^{[69]}$. In the largest multicentre study for PDN, the VEN treatment group (150-225 mg daily dose) reached a significantly greater improvement than that for the placebo group at week $6(50 \% \text { versus } 27 \%)^{[70]}$. The NNT of benefit of VEN in the treatment of PDN is $3.1^{[34]}$. The recommended daily dose of VEN XR for PDN is $150-225 \mathrm{mg}$ once a day ${ }^{[3]}$.

The most common treatment-emergent AEs of VEN XR were nausea, somnolence and hypertension at high dosage ${ }^{[7,70]}$. Nausea showed a dose-proportional manner (at $75 \mathrm{mg} 22 \%$ and at $150-225 \mathrm{mg} \mathrm{10 \% )}{ }^{[71]}$. Precautions for the use of VEN include cardiac disease, hypertension and the administration of tramadol ${ }^{[7]}$.

The NeuSPIG consensus declared that VEN reached the strong recommendations for use in the treatment of PDN ${ }^{[3]}$.

Overall, the above-mentioned antidepressants are all effective in the treatment of PDN. As concerns the safety profile of SNRIs, it is a very important fact that the SNRIs have low affinity for different neuronal receptors, which results in low AEs. In spite of this, TCAs are held to be „dirty drugs” as regards their multireceptorial effects, resulting in high amounts of side-effects. In the daily clinical practice, besides the effectiveness and the safety profile of the first-line drugs for PDN, the economic aspects are also very important factors. In most countries, TCAs are readily available with low charge. DUL is a cost-effective pharmacon for the treatment of PDN in the UK ${ }^{[34]}$. The results of randomized clinical trials and real-world studies showed DUL to be more cost-effective than antiepileptics like pregabalin (PREG) in PDN therapy ${ }^{[72]}$.

\subsection{Antiepileptics}

Among antiepileptics, only the GABA analogues, gabapentin (GBP), GBP XR and its prodrug GBP enacarbil and pregabalin (PREG) have reached the strong recommendation level in the treatment of PDN ${ }^{[3,73]}$. Each has a similar mechanism of action to inhibit the release of presynaptic excitatory neurotransmitters ${ }^{[74]}$. A wide variety of other antiepileptic drugs were inconclusive for recommendation, e.g. carbamazepine, lacosamide, lamotrigine, levetiracetam, oxcarbazepine, topiramate, valproate and zonisamide ${ }^{[3,73]}$.

\subsubsection{Gabapentin (GBP)}


GBP was developed in 1993 and was first marketed in the US in 1994. The FDA later approved it for PDN and postherpetic neuralgia ${ }^{[75]}$. Its chemical structure is 1(aminomethyl)cyclohexaneacetic acid.

The mechanism of analgesic action of GBP in humans has not been clarified, but in animal models has been proved that GBP binds to the $\alpha_{2} \delta$ subunit of L-type voltage-dependent calcium channels ${ }^{[34,76]}$. The consequences of this effect are the reduction of the calcium currents and inhibition of the presynaptic release of neurotransmitters, such as glutamate and substance $\mathrm{P}^{[76]}$. Interestingly, it is structurally related to GABA, but does not bind to GABAA or GABA-B receptors, and does not block the uptake or degradation of GABA ${ }^{[76]}$. The main signs of the central sensitization are allodynia and hyperalgesia, which could be diminished by GBP ${ }^{[76]}$.

The pharmacokinetic parameters of orally administered GBP tablets of $600 \mathrm{mg}$ three times daily revealed that $\mathrm{C}_{\max }$ was $8.46 \mathrm{mg} / \mathrm{L}$, the AUC was $53.1 \mathrm{mg} / \mathrm{L} \mathrm{x} \mathrm{h}, \mathrm{T}_{\max }$ was $2 \mathrm{~h}$ and $\mathrm{T}_{1 / 2}$ was $6 \mathrm{~h}{ }^{[76]}$. The plasma protein binding of GBP is less than $3 \%$, it is not significantly metabolized, and it is renally excreted in unchanged form ${ }^{[76]}$. The bioavailability of GBP is inversely proportional to the dose: $60 \%$ at $900 \mathrm{mg} /$ day and $27 \%$ at $4800 \mathrm{mg} /$ day (administered in three divided doses) ${ }^{[76]}$. In contrast, its prodrug, enacarbil, showed essentially linear dose-proportional pharmacokinetic properties ${ }^{[77,78]}$. GBP has a volume of distribution of $58 \mathrm{~L}$ after $150 \mathrm{mg}$ intravenous administration ${ }^{[76]}$.

In the available literature, there are no in vitro data on GBP and CYP450 interactions in humans, so GBP is neither an inducer nor an inhibitor of the hepatic metabolism of different drugs ${ }^{[79]}$. However, there are data that hydrocodone and morphine can increase GBP absorption and the plasma concentration of GBP ${ }^{[80]}$. Naproxen as a frequently used nonsteroidal antiinflammatory drug (NSAID) can increase Cmax and the AUC of GBP ${ }^{[80]}$.

The recent Cochrane Database meta-analysis revealed that the efficacy of GBP for the therapy of PDN was superior to placebo (38\% versus $21 \%$, NNT 5.9, $95 \%$ CI 4.6 to 8.3$)^{[81]}$. A similar effect was seen for standard GBP and a GBP XR formulation ${ }^{[81]}$.

The recommended daily dose of GBP for PDN is $1200-3600 \mathrm{mg}$ in three divided doses, while that of GBP XR or enacarbil is $1200-3600 \mathrm{mg}$ in two divided doses ${ }^{[3]}$.

A recent large retrospective clinical study in the United States revealed that among newly diagnosed PDN patients the most commonly prescribed drug was GBP $(45 \%)^{[82]}$. From the aspect of the adherence to treatment during the first year, GBP showed a high adherence level versus PREG and DUL ${ }^{[82]}$. 
The most common AEs of GBP were dizziness (19\%), somnolence (14\%), peripheral oedema $(7 \%)$, gait disturbance $(9 \%)$, and also sedation and weight gain ${ }^{[7,81]}$. Serious AEs were no more frequent as compared with placebo ${ }^{[81]}$. A precaution concerning the application of GBP in a case of renal insufficiency is that a reduced dosage is recommended ${ }^{[7]}$.

In a safety issue based on patient withdrawals due to AEs, a meta-analysis revealed that there was less withdrawal among patients who take GBP, and the most patient withdrawals due to AEs were in the case of AMI ${ }^{[83]}$. That study concluded in the focus of the benefit-risk analysis between six antidepressants and antiepileptics that the best benefit-risk ratio was shown by GBP, and the worst one by AMI ${ }^{[83]}$.

The NeuSPIG consensus declares that GBP, GBP XR and enacarbil reached the strong recommendations for use in the treatment of $\mathrm{PDN}^{[3]}$.

\subsubsection{Pregabalin (PREG)}

The GABA analogue PREG received the US FDA approval for the treatment of PDN and postherpetic neuralgia in $2004^{[84]}$. Its chemical structure is $(S)$-3-(aminomethyl)-5methylhexanoic acid.

The mode of anti-nociceptive action of PREG is based on the molecular binding to the $\alpha_{2} \delta$ subunit of the P/Q type of the voltage-gated calcium channel in the CNS, resulting in a decreased influx of calcium ion into the neuronal cell ${ }^{[85]}$. The lack of the required quantity of calcium ion in the nerve cells results in the blockade of the propagation of neurotransmission due to inadequate synaptic vesicule fusion to the presynaptic membrane of the synapses ${ }^{[85]}$. PREG has a high affinity for $\alpha_{2} \delta$ type 1 and 2 proteins versus TCAs (e.g. AMI), SNRIs (e.g. VEN) or other antiepileptics (e.g. carbamazepine) ${ }^{[85]}$. PREG shows strong binding to the pain matrix-like cortex or dorsal horn of the spinal cord ${ }^{[85]}$. The PREG-induced blockade of neurotransmitters such as glutamate, glycine, norepinephrine, substance P, calcitonin generelated peptide or acetylcholine resulted in inhibition of neuronal excitability and diminished the process of the central sensitization in $\mathrm{NP}^{\left[{ }^{[5]} \text {. }\right.}$

As a gabapentinoid, PREG does not bind directly to GABA or benzodiazepine or opioid receptors. PREG as a glutamic acid decarboxylase (GAD) activator can increase neural GABA levels ${ }^{[86]}$.

The pharmacokinetic parameters of an orally administered single dose of a PREG capsule of $150 \mathrm{mg}$ revealed that $\mathrm{C}_{\max }$ was $3.99 \mathrm{ng} / \mathrm{L}$, AUC was $28.31 \mathrm{ng} / \mathrm{mL} \mathrm{x} \mathrm{h,} \mathrm{T}_{\max }$ was $1.00 \mathrm{~h}$ and $\mathrm{T}_{1 / 2}$ was $5.66 \mathrm{~h}^{[87]}$. The kinetics of PREG showed linear features (proportional to the dosage up to $900 \mathrm{mg}$ per day) ${ }^{[88]}$. The plasma protein binding of PREG is absent and its metabolism 
is negligible, with no effect on the CYP450 system ${ }^{[79,83,88]}$. The bioavailabilty of PREG is more than $90 \%$ and the volume of distribution $0.5 \mathrm{~L} / \mathrm{kg}{ }^{[83]} .90 \%$ is excreted in the urine as the

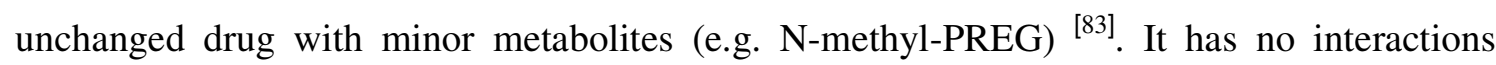
metabolically with other antiepileptic drugs ${ }^{[79,80]}$.

The results of randomized clinical trials for the use of PREG (300-600 mg per day) in PDN revealed significantly better efficacy as compared with placebo ${ }^{[84]}$. The evidence-based guidelines of the American Academy of Neurology announced that PREG is the only drug which reached the Level A (top-tier) of evidence in the treatment of PDN ${ }^{[36]}$. The NNT of PREG in the treatment of PDN is $5.0^{[34]}$.

The recommended daily dose of PREG for PDN is $300-60 \mathrm{mg}$ in two divided doses ${ }^{[3]}$.

The common major AEs of PREG are sedation, somnolence (less than or around 50\%), dizziness (less than or around 49\%), headache (less than or around 29\%), peripheral oedema and weight gain ${ }^{[7,84]}$.

There are data for predictive factors for AEs associated with the use of PREG in PDN patients, e.g. long duration of therapy - somnolence; advanced age - unsteadiness; elevated serum creatinine level - weight gain and oedema ${ }^{[89]}$.

Precautions for PREG therapy include a reduced dosage in the case of renal failure patients ${ }^{[7]}$. The NeuSPIG consensus declares, that PREG reached the strong recommendations for use in the treatment of PDN ${ }^{[3]}$.

Taken together, the effectiveness and safety profile of antiepileptics involved in the treatment of PDN are based on their pharmacokinetic and pharmacodynamic properties. From their licence permission for clinical use their prescription has been increasing, but many PDN patients do not receive them or take antiepileptics below the recommended dosage ${ }^{[82,90]}$.

\section{Conclusions}

PDN is a debilitating consequence of diabetes, which greatly affects the quality of life of the patient. The exact pathomechanism of PDN is unknown, and causative treatment is therefore unavailable. For the symptomatic treatment of PDN, there are first-line strongly recommended drugs, such as antidepressants (TCAs: AMI; and SNRIs: DUL and VEN) and antiepileptics (only gabapentinoids: GBP and PREG). Among antidepressants, TCAs and SNRIs show similar efficacy as concerns PDN, but from the aspect of their AEs, based on their pharmacokinetic and pharmacodynamic properties, huge discrepancies may be seen. Gabapentinoids have a similar mode of action and effectiveness in the treatment of PDN, but 
some of their pharmacological properties, such as their bioavailability, absorption and kinetics vary, which leads to different features of their therapeutic and safety profiles.

\section{Expert opinion}

The treatment of PDN patients is a great challenge for primary care physicians, diabetologists, neurologists and even pain specialists. Epidemiological surveys have established that a huge number of patients with NP do not receive appropriate treatment ${ }^{[3]}$. The difficulties in the treatment of PDN include the unclear pathomechanism and pathogenesis, and there are no specific efficacious pain relief drugs for PDN. It is interesting that the placebo response rate is relatively high in NP patients, and especially PDN patients. Focusing on the efficacy of a drug used for the alleviation of pain in PDN, we underline the fact, that the placebo effects are usually notably strong. This shows the narrow gap between the achieved effectiveness and the result of the placebo treatment, which gives a challenge for a novel pharmacological innovation for the preparation of new and effective drugs for the successful treatment PDN. Unfortunately, the recent evidence-based guidelines consist of only a few first-line strongly recommended drugs for the treatment of PDN, such as amitriptyline, duloxetine, venlafaxine, gabapentin and pregabalin. All of these have unfavourable AEs and contraindications. The correct choice of drugs is a real art of medicine. It is a perpetually recurring question for the medical staff to decide which PDN patient should receive which effective, well-tolerated and safe drug. Unfortunately, the demographic data or disease characteristics are not predictors for the pain alleviation treatment, and they do not help in the choice of the proper medication for PDN patients. Another problem is that there are no optimum biomarkers of this field at the present. There are some promising data which showed a positive correlation between plasma tumor necrosis factor (TNF)alpha levels and macrophages, inducible nitric oxide synthase

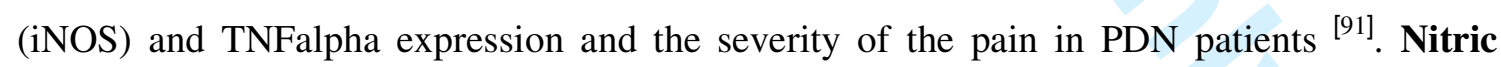
oxide (NO) is an indigenous gas, and its elevated level has been implicated in the pathomechanism of PDN ${ }^{[92,93]}$. Other potential biomarkers may include certain angiogenic and anti-angiogenic factors such as vascular endothelial growth factor, soluble endoglin, endothelin-1, and NO, molecules with plasma levels found elevated in diabetic patients compared to controls ${ }^{[94]}$. The furoxan NO donor, PRG150, was investigated in the streptozotocin-induced diabetic rat model of PDN and demonstrated a dose-dependent analgesic effect, which may represent a novel promising approach in PDN ${ }^{[93]}$. Furthermore, a NO-donating pregabalin, NCX1404, exerted strong 
antiallodynic response in the streptozocin-induced murine model of PDN. Repeated dosing with NCX1404 re-established normal nociceptive response in this model ${ }^{[95]}$. Oxidative stress has a role in the development of microvascular complications in patients with diabetic neuropathy. A clinical study revealed a decreased serum prolidase enzyme activity, which may be associated with increased NO levels and oxidative stress in diabetic patients with neuropathy ${ }^{[96]}$. In a randomized placebo-controlled study, a NO-releasing patch (NitroSense Derma Protect) showed a significant reduction in pain of PDN patients ${ }^{[97]}$.

We highlight the importance of finding the optimum dose of drugs for PDN, especially in the elderly due to the genotyping of the CYP450 enzymes, which play a crucial role in the metabolism of these drugs. It is similarly important for better personalizing treatment of PDN patients to integrate the CYP genotyping with therapeutic drug monitoring for the safe use of medications.

In the near future it is recommended to guide pharmacogenetic studies based on the genetic polymorphisms in different genes (e.g. novel techniques such as AmpliChip CYP450 Genotyping Test), which can reflect the treatment response to drugs used in PDN.

At the bedside, one of the major challenges is the interindividual variability to the response to the drug used for PDN. As concerns the comorbidities of PDN, the polymedication and the genetic polymorphism are other important issues from the aspect of the drug metabolization and the drug-drug interactions. For the patients who are ultrarapid metabolizers, the pharmacological medications are usually ineffective, while those who are poor metabolizers are at high risk of life-threatening toxicity. There is therefore a need for a new aspect of the treatment of PDN patients such as determining the genotyping of CYP variant alleles.

In the coming years, it will be strongly recommended to use the genotyping analysis of CYP450 drug-drug and drug-gene interactions in the daily clinical practice in order to estimate the effectiveness and safety of the prescribed drugs for PDN. This advanced diagnostic method might serve as the basis of the request for personalized medicine.

The analysis of drug-drug interactions is a crucial part for pharmacokinetic and pharmacodynamic studies of the drugs used for PDN. There is a need for methods to evaluate pharmacons of this type, e.g. micellar electrokinetic chromatography electrospray ionizationtandem mass spectrometry, which is a cost-effective technique for measuring VEN and desvenlafaxine enantiomers ${ }^{[98]}$.

One of the potential fields for the causal therapy of PDN is the sodium channel isoforms (Nav1.3, Nav1.7, Nav1.8 and Nav1.9) on the peripheral nociceptive neurons. Preclinical and 
clinical trials have revealed that the blockers of these subtypes of the sodium channels give us new fashionable effective drugs against PDN ${ }^{[27]}$.

The sodium channel voltage sensor monoclonal antibody which targets the peripheral and central Nav1.7 channel diminishes itch and neuropathic pain in an animal model ${ }^{[26]}$. This channel-specific antibody may therefore be a potential therapeutic option in human PDN ${ }^{[26,}$ 99].

Another potential research area may be the modification of the glycosylation of the subclass of T-type voltage-gated calcium channels (Cav3.2), which are related to the hyperexcitable state of nociceptors in diabetic animal models ${ }^{[100]}$. In the preclinical state of this research field, the classical streptozotocin-induced diabetic rodent model as a reliable way to induce strong mechanical allodynia and thermal hyperalgesia is not sufficient to mimic all the aspects of the clinical picture of PDN. For future perspectives there is a need for new animal models which serve the innovation of the targeted treatment of PDN.

One of the most promising therapeutic options arises from the technique of fully humanized monoclonal antibodies $(\mathrm{mAb})$. There are preclinical data pinpointing the role of integrins, receptors for extracellular matrix proteins, in the processes of inflammatory and neuropathic hyperalgesia and the chronification of pain ${ }^{[101-103]}$. The mAbs against the beta1 integrin subunit demonstrated an inhibitory effect on prostaglandin E2- and epinephrine-induced hyperalgesia in rats ${ }^{[101,102]}$. These findings may provide new therapeutic options for the treatment of PDN. Antibodies against NGF (e.g. tanezumab, fulranumab and fusinumab) in the treatment of osteoarthritis of the hip or knee showed superiority in efficacy in pain relief (Western Ontario and McMaster - WOMAC pain) and Patient's Global Assessment compared to placebo ${ }^{[104]}$. Unfortunately, unexpected AEs with tanezumab were reported, such as rapid osteonecrosis with an unknown cause at present, a complication necessitating joint replacement surgery ${ }^{[105]}$. Based on this finding, the US Food and Drug Administration placed the studies of all anti-NGF monoclonal antibodies on clinical hold ${ }^{[105]}$. In an early truncated Phase II double-blind placebo-controlled trial with fulranumab for the treatment of PDN resulted in a dosedependent efficacy, and there was no case necessitating joint replacement therapy ${ }^{[106]}$. Another randomized controlled study with tanezumab forPDN demonstrated pain reduction versus placebo; however, there was no significant difference in Patient's Global Assessment scale ${ }^{[107]}$.

Another class of mAb against the receptor for advanced glycation and products, which is expressed through the sensory nervous system, resulted in a dose-related attenuation of NP in 
a mouse NP model ${ }^{[108]}$. Neutralized mAb against interleukin-17A diminished the hyperalgesia in a spinal nerve ligation model in mice ${ }^{[109]}$. Another type of mAb against highmobility group box-1 strongly alleviated the mechanical hypersensitivity and the expression of matrix metalloproteinase- 9 in the partial sciatic nerve ligation model in mice ${ }^{[110]}$. On the basis of the preclinical and early clinical results, we emphasize that mAbs targeting the different sites of the pain matrix may give a strong possibility for the causal therapy of PDN.

Further perspectives emerge from the intradermal application of the botulinum toxin type A for PDN. Early clinical studies suggested some effectiveness for benefit for PDN patients ${ }^{[11]}$. Due to these early clinical data, further larger randomized controlled studies are required for the evaluation of the efficacy of botulinum toxin type $\mathrm{A}$ in this disease.

The Transient Receptor Potential (TRP) cation channels, including Ankyrin repeat domain 1 (TRPA1) and Vanilloid type 1 (TRPV1), have crucial roles in the nociceptive process $[112,113]$. Recent reports demonstrated that a topical $8 \%$ patch of capsaicin, the classical TRPV1 agonist, may have a beneficial outcome in PDN patients ${ }^{[114]}$. The release of the final results is waited urgently. In healthy human volunteers, the pharmacokinetic profile of TRPV1 antagonists (ABT-102 and JNJ-38893777) were evaluated, and they also showed a good tolerability ${ }^{[115,116]}$. In a phase 2 a (proof-of-concept) study, one of the potent and selective TRPA1 antagonist (GRC17536) demonstrated efficacy in patients with PDN ${ }^{[117]}$. Phase 3 studies are warranted in the near future to provide more accurate data. At the experimental level, a novel oxime compound, as a potent TRPA1 and TRPV1 antagonist, has been proven to have promising efficacy on primary sensory neurons ${ }^{[113]}$. This compound might be a new candidate for drug development for the treatment of neuropathic pain ${ }^{[113]}$.

In the case of pharmacologically refractory PDN, one of the ultimate choices is spinal cord stimulation. A multicenter randomized clinical trial concluded that spinal cord stimulation significantly alleviated the pain in PDN patients ${ }^{[118]}$. Neuromodulation methods, such as spinal cord stimulation are invasive and expensive techniques, and careful patient selection is therefore needed. From the aspect of drug innovation, the targeting of good clinical efficacy, tolerability, safety and comparable cost-effectiveness are very important research fields. Innovative drug technology is additionally needed to achieve these goals. One example in which immediate release versus an XR formulation of VEN were compared, the XR formulation showed less AEs (e.g. nausea and dizziness) due to the novel pharmacological technology ${ }^{[50]}$. 
Currently prescribed first-line strongly recommended symptomatic treatment for PDN (amitriptyline, duloxetine, venlafaxine, gabapentin, pregabalin) are efficacious, but all have limitations due to their precautions and AEs. To attain the better adherence of PDN patients, the ultimate goal is a large pharmacogenetic study, with the aim of the drug-drug and druggene interactions.

\section{Conflict of interest}

The authors declare that they have no conflict of interest and have received no payment in the preparation of their manuscript.

\section{Acknowledgements}

This work was supported by the project TÁMOP-4.2.2.A-11/1/KONV-2012-0052, by the Hungarian Brain Research Programme (NAP, Grant No. KTIA_13_NAP-A-III/9. and by the MTA-SZTE Neuroscience Research Group of the Hungarian Academy of Sciences and the University of Szeged. 


\section{Figures}

Figure 1. Scheme of sensitization and hyperexcitability of mechanism of neuropathic pain

Modified (Ref.: ${ }^{[5]}$ )

Abbreviations:

ATP: adenosine triphosphate, BDNF: brain-derived neurotrophic factor, DRG: dorsal root gablgion, $\mathrm{Na}_{\mathrm{v}} 1.8$ and $\mathrm{Na}_{\mathrm{v}} 1.9$ : voltage-gated sodium channels, NMDA-R: N-methyl-Daspartate receptor, NGF: nerve growth factor, P2X4: purinergic receptor, TrkB: tropomysin receptor kinase $\mathrm{B}$

Figure 2. Chemical structures of the first-line drugs for painful diabetic neuropathy (Ref.: $\left.{ }^{[88,119-122]}\right)$ 


\title{
Table legends
}

Table 1. Pharmacokinetic and pharmacodynamic properties of the first-line drugs for the treatment of PDN

\author{
Abbreviations: AUC: the area under the concentration vs. time curve, $\mathrm{C}_{\max }$ : the maximum \\ plasma concentration, h: hours, iv: intravenously, L: litre, NA: not available, PDN: painful \\ diabetic neuropathy, Ref.: references, $\mathrm{T}_{\max }$ : the time to $\mathrm{C}_{\max }, \mathrm{T}_{1 / 2}$ : the plasma elimination half- \\ life, XR: extended release
}

Table 2. Recommended daily doses and adverse events of the first-line drugs for the treatment of PDN
Abbreviations: NNT: number needed to treat; PDN: painful diabetic neuropathy; XR:
extended release
(Ref.: ${ }^{[3,4,7,34,46,53,63,64,81,84]}$ 


\section{Bibliography}

Papers of special note have been highlighted as either of interest $(\bullet)$ or of considerable interest $(\bullet \bullet)$ to readers.

1. Jensen TS, Baron R, Haanpaa M, et al. A new definition of neuropathic pain. Pain 2011;152:2204-5.

2. Baron R, Binder A, Wasner G. Neuropathic pain: diagnosis, pathophysiological mechanisms, and treatment. Lancet Neurol 2010;9:807-19.

3. Finnerup NB, Attal N, Haroutounian S, et al. Pharmacotherapy for neuropathic pain in adults: a systematic review and meta-analysis. Lancet Neurol 2015;14:162-73.

- An updated review of evidence-based recommendation for the pharmacological treatment of neuropathic pain.

4. Alabdali M, Qrimli M, Barnett C, et al. Choosing drugs for the treatment of diabetic neuropathy. Expert Opin Pharmacother 2015;16:1805-14.

•• This paper reported the recent therapeutic guidelines of diabetic neuropathy.

5. Vecsei L, Majlath Z, Balog A, Tajti J. Drug targets of migraine and neuropathy: treatment of hyperexcitability. CNS Neurol Disord Drug Targets 2015;14:664-76.

6. Marmiroli P, Cavaletti G. Drugs for the treatment of peripheral neuropathies. Expert Opin Pharmacother 2015:1-14.

The authors presented the advanced therapy of specific neuropathies based on the most important published trials and from clinical experience.

7. Attal N, Bouhassira D. Pharmacotherapy of neuropathic pain: which drugs, which treatment algorithms? Pain 2015;156 Suppl 1:S104-14.

•• This article revealed the treatment algorithms of recommended pharmacotherapy of neuropathic pain.

8. Dyck PJ, Kratz KM, Karnes JL, et al. The prevalence by staged severity of various types of diabetic neuropathy, retinopathy, and nephropathy in a population-based cohort: the Rochester Diabetic Neuropathy Study. Neurology 1993;43:817-24.

9. MacDonald BK, Cockerell OC, Sander JW, Shorvon SD. The incidence and lifetime prevalence of neurological disorders in a prospective community-based study in the UK. Brain 2000;123 ( Pt 4):665-76.

10. Sadosky A, McDermott AM, Brandenburg NA, Strauss M. A review of the epidemiology of painful diabetic peripheral neuropathy, postherpetic neuralgia, and less commonly studied neuropathic pain conditions. Pain Pract 2008;8:45-56.

11. Sadosky A, Mardekian J, Parsons B, et al. Healthcare utilization and costs in diabetes relative to the clinical spectrum of painful diabetic peripheral neuropathy. $J$ Diabetes Complications 2015;29:212-7.

12. Smith SC, Lamping DL, Maclaine GD. Measuring health-related quality of life in diabetic peripheral neuropathy: a systematic review. Diabetes Res Clin Pract 2012;96:261-70.

13. Tajti J, Szok D, Csati A, Vecsei L. Prophylactic Drug Treatment of Migraine in Children and Adolescents: An Update. Curr Pain Headache Rep 2016;20:1.

14. Tajti J, Szok D, Majlath Z, et al. Migraine and neuropeptides. Neuropeptides 2015;52:1930 .

15. Szok D, Csati A, Vecsei L, Tajti J. Treatment of Chronic Migraine with OnabotulinumtoxinA: Mode of Action, Efficacy and Safety. Toxins (Basel) 2015;7:2659-73.

16. Tajti J, Tuka B, Botz B, et al. Role of pituitary adenylate cyclase-activating polypeptide in nociception and migraine. CNS Neurol Disord Drug Targets 2015;14:540-53.

17. Finnerup NB, Jensen TS. Mechanisms of disease: mechanism-based classification of neuropathic pain-a critical analysis. Nat Clin Pract Neurol 2006;2:107-15. 
18. Hirose M, Kuroda Y, Murata E. NGF/TrkA Signaling as a Therapeutic Target for Pain. Pain Pract 2016;16:175-82.

19. Khan N, Smith MT. Neurotrophins and Neuropathic Pain: Role in Pathobiology. Molecules 2015;20:10657-88.

20. Baron R. Mechanisms of disease: neuropathic pain--a clinical perspective. Nat Clin Pract Neurol 2006;2:95-106.

21. Biggs JE, Lu VB, Stebbing MJ, et al. Is BDNF sufficient for information transfer between microglia and dorsal horn neurons during the onset of central sensitization? Mol Pain 2010;6:44.

22. Calvo M, Dawes JM, Bennett DL. The role of the immune system in the generation of neuropathic pain. Lancet Neurol 2012;11:629-42.

23. Sommer C. Painful neuropathies. Curr Opin Neurol 2003;16:623-8.

24. Cox JJ, Reimann F, Nicholas AK, et al. An SCN9A channelopathy causes congenital inability to experience pain. Nature 2006;444:894-8.

25. Minett MS, Nassar MA, Clark AK, et al. Distinct Nav1.7-dependent pain sensations require different sets of sensory and sympathetic neurons. Nat Commun 2012;3:791.

26. Lee JH, Park CK, Chen G, et al. A monoclonal antibody that targets a NaV1.7 channel voltage sensor for pain and itch relief. Cell 2014;157:1393-404.

27. Kharatmal SB, Singh JN, Sharma SS. Voltage-Gated Sodium Channels as Therapeutic Targets for Treatment of Painful Diabetic Neuropathy. Mini Rev Med Chem 2015;15:1134-47. 28. Zhang JL, Yang JP, Zhang JR, et al. Gabapentin reduces allodynia and hyperalgesia in painful diabetic neuropathy rats by decreasing expression level of Nav1.7 and p-ERK1/2 in DRG neurons. Brain Res 2013;1493:13-8.

29. Galloway C, Chattopadhyay M. Increases in inflammatory mediators in DRG implicate in the pathogenesis of painful neuropathy in Type 2 diabetes. Cytokine 2013;63:1-5.

30. Trang T, Beggs S, Salter MW. Brain-derived neurotrophic factor from microglia: a molecular substrate for neuropathic pain. Neuron Glia Biol 2011;7:99-108.

31. Petrenko AB, Yamakura T, Baba H, Shimoji K. The role of N-methyl-D-aspartate (NMDA) receptors in pain: a review. Anesth Analg 2003;97:1108-16.

32. Beniczky S, Tajti J, Timea Varga E, Vecsei L. Evidence-based pharmacological treatment of neuropathic pain syndromes. J Neural Transm (Vienna) 2005;112:735-49.

33. Wagner AH, Coffman AC, Ainscough BJ, et al. DGIdb 2.0: mining clinically relevant drug-gene interactions. Nucleic Acids Res 2016;44:D1036-44.

34. Javed S, Petropoulos IN, Alam U, Malik RA. Treatment of painful diabetic neuropathy. Ther Adv Chronic Dis 2015;6:15-28.

- The authors gave us a detailed pain management concerning the painful diabetic neuropathy.

35. Attal N, Cruccu G, Baron R, et al. EFNS guidelines on the pharmacological treatment of neuropathic pain: 2010 revision. Eur J Neurol 2010;17:1113-e88.

36. Bril V, England J, Franklin GM, et al. Evidence-based guideline: Treatment of painful diabetic neuropathy: report of the American Academy of Neurology, the American Association of Neuromuscular and Electrodiagnostic Medicine, and the American Academy of Physical Medicine and Rehabilitation. Neurology 2011;76:1758-65.

37. Guyatt GH, Oxman AD, Vist GE, et al. GRADE: an emerging consensus on rating quality of evidence and strength of recommendations. BMJ 2008;336:924-6.

38. Fangmann P, Assion HJ, Juckel G, et al. Half a century of antidepressant drugs: on the clinical introduction of monoamine oxidase inhibitors, tricyclics, and tetracyclics. Part II: tricyclics and tetracyclics. J Clin Psychopharmacol 2008;28:1-4.

39. Gupta SK, Shah JC, Hwang SS. Pharmacokinetic and pharmacodynamic characterization of OROS and immediate-release amitriptyline. Br J Clin Pharmacol 1999;48:71-78. 
40. Dharmshaktu P, Tayal V, Kalra BS. Efficacy of antidepressants as analgesics: a review. J Clin Pharmacol 2012;52:6-17.

41. Punke MA, Friederich P. Amitriptyline is a potent blocker of human Kv1.1 and Kv7.2/7.3 channels. Anesth Analg 2007;104:1256-64, tables of contents.

42. Jang SW, Liu X, Chan CB, et al. Amitriptyline is a TrkA and TrkB receptor agonist that promotes TrkA/TrkB heterodimerization and has potent neurotrophic activity. Chem Biol 2009; 16:644-56.

43. Italiano D, Spina E, de Leon J. Pharmacokinetic and pharmacodynamic interactions between antiepileptics and antidepressants. Expert Opin Drug Metab Toxicol 2014;10:145789.

44. Hicks JK, Swen JJ, Thorn CF, et al. Clinical Pharmacogenetics Implementation Consortium guideline for CYP2D6 and CYP2C19 genotypes and dosing of tricyclic antidepressants. Clin Pharmacol Ther 2013;93:402-8.

45. Max MB, Lynch SA, Muir J, et al. Effects of desipramine, amitriptyline, and fluoxetine on pain in diabetic neuropathy. N Engl J Med 1992;326:1250-6.

46. Dodick DW, Freitag F, Banks J, et al. Topiramate versus amitriptyline in migraine prevention: a 26-week, multicenter, randomized, double-blind, double-dummy, parallel-group noninferiority trial in adult migraineurs. Clin Ther 2009;31:542-59.

47. Gore M, Dukes E, Rowbotham D, et al. Prevalence of contraindicated medical conditions and use of precluded medications in patients with painful neuropathic disorders prescribed amitriptyline. Pain Pract 2006;6:265-72.

48. Moore RA, Derry S, Aldington D, et al. Amitriptyline for neuropathic pain in adults. Cochrane Database Syst Rev 2015;7:CD008242.

- The importance of the role of amitriptyline for neuropathic pain treatment is highlighted.

49. Bymaster FP, Beedle EE, Findlay J, et al. Duloxetine (Cymbalta), a dual inhibitor of serotonin and norepinephrine reuptake. Bioorg Med Chem Lett 2003;13:4477-80.

50. Sansone RA, Sansone LA. Serotonin norepinephrine reuptake inhibitors: a pharmacological comparison. Innov Clin Neurosci 2014;11:37-42.

51. Bymaster FP, Lee TC, Knadler MP, et al. The dual transporter inhibitor duloxetine: a review of its preclinical pharmacology, pharmacokinetic profile, and clinical results in depression. Curr Pharm Des 2005;11:1475-93.

52. Pergolizzi JV, Jr., Raffa RB, Taylor R, Jr., et al. A review of duloxetine $60 \mathrm{mg}$ once-daily dosing for the management of diabetic peripheral neuropathic pain, fibromyalgia, and chronic musculoskeletal pain due to chronic osteoarthritis pain and low back pain. Pain Pract 2013;13:239-52.

53. Carter NJ, McCormack PL. Duloxetine: a review of its use in the treatment of generalized anxiety disorder. CNS Drugs 2009;23:523-41.

54. De Berardis D, Conti CM, Serroni N, et al. The effect of newer serotonin-noradrenalin antidepressants on cytokine production: a review of the current literature. Int J Immunopathol Pharmacol 2010;23:417-22.

55. Salat K, Moniczewski A, Librowski T. Nitrogen, oxygen or sulfur containing heterocyclic compounds as analgesic drugs used as modulators of the nitroxidative stress. Mini Rev Med Chem 2013;13:335-52.

56. Wang SY, Calderon J, Kuo Wang G. Block of neuronal Na+ channels by antidepressant duloxetine in a state-dependent manner. Anesthesiology 2010;113:655-65.

57. Kinoshita J, Takahashi Y, Watabe AM, et al. Impaired noradrenaline homeostasis in rats with painful diabetic neuropathy as a target of duloxetine analgesia. Mol Pain 2013;9:59.

58. Knadler MP, Lobo E, Chappell J, Bergstrom R. Duloxetine: clinical pharmacokinetics and drug interactions. Clin Pharmacokinet 2011;50:281-94. 
59. Maciukiewicz M, Marshe VS, Tiwari AK, et al. Genetic variation in IL-1beta, IL-2, IL-6, TSPO and BDNF and response to duloxetine or placebo treatment in major depressive disorder. Pharmacogenomics 2015;16:1919-29.

60. Perlis RH, Fijal B, Dharia S, Houston JP. Pharmacogenetic investigation of response to duloxetine treatment in generalized anxiety disorder. Pharmacogenomics J 2013;13:280-5.

61. de Leon J, Susce MT, Murray-Carmichael E. The AmpliChip CYP450 genotyping test: Integrating a new clinical tool. Mol Diagn Ther 2006;10:135-51.

62. de Leon J, Armstrong SC, Cozza KL. Clinical guidelines for psychiatrists for the use of pharmacogenetic testing for CYP450 2D6 and CYP450 2C19. Psychosomatics 2006;47:75-85. 63. Lunn MP, Hughes RA, Wiffen PJ. Duloxetine for treating painful neuropathy, chronic pain or fibromyalgia. Cochrane Database Syst Rev 2014;1:CD007115.

- A metaanalysis of randomized clinical trials demonstrated the effect of duloxetine for painful neuropathies.

64. Goldstein DJ, Lu Y, Detke MJ, et al. Duloxetine vs. placebo in patients with painful diabetic neuropathy. Pain 2005;116:109-18.

65. Barman Balfour JA, Jarvis B. Venlafaxine Extended-Release: A Review of its Clinical Potential in the Management of Generalised Anxiety Disorder. CNS Drugs 2000;14:483-503. 66. Redrobe JP, Bourin M, Colombel MC, Baker GB. Dose-dependent noradrenergic and serotonergic properties of venlafaxine in animal models indicative of antidepressant activity. Psychopharmacology (Berl) 1998;138:1-8.

67. Schreiber S, Bleich A, Pick CG. Venlafaxine and mirtazapine: different mechanisms of antidepressant action, common opioid-mediated antinociceptive effects--a possible opioid involvement in severe depression? J Mol Neurosci 2002;18:143-9.

68. Cooper AJ, Narasimhan S, Rickels K, Lohoff FW. Genetic polymorphisms in the PACAP and PAC1 receptor genes and treatment response to venlafaxine XR in generalized anxiety disorder. Psychiatry Res 2013;210:1299-300.

69. Gallagher HC, Gallagher RM, Butler M, et al. Venlafaxine for neuropathic pain in adults. Cochrane Database Syst Rev 2015;8:CD011091.

70. Rowbotham MC, Goli V, Kunz NR, Lei D. Venlafaxine extended release in the treatment of painful diabetic neuropathy: a double-blind, placebo-controlled study. Pain 2004;110:697706.

71. Grothe DR, Scheckner B, Albano D. Treatment of pain syndromes with venlafaxine. Pharmacotherapy 2004;24:621-9.

72. Bellows BK, Dahal A, Jiao T, Biskupiak J. A cost-utility analysis of pregabalin versus duloxetine for the treatment of painful diabetic neuropathy. J Pain Palliat Care Pharmacother 2012;26:153-64.

73. Wiffen PJ, Derry S, Moore RA, et al. Antiepileptic drugs for neuropathic pain and fibromyalgia - an overview of Cochrane reviews. Cochrane Database Syst Rev 2013;11:CD010567.

- An overview of effectiveness and safety of antiepileptic drugs for the treatment of neuropathic pain.

74. Schreiber AK, Nones CF, Reis RC, et al. Diabetic neuropathic pain: Physiopathology and treatment. World J Diabetes 2015;6:432-44.

75. Stacey BR. Gabapentin: a viewpoint by Brett R. Stacey. CNS Drugs 2003;17:983.

76. Curran MP, Wagstaff AJ. Gabapentin: in postherpetic neuralgia. CNS Drugs 2003;17:97582.

77. Chen C. Meta-analyses of dose-exposure relationships for gabapentin following oral administration of gabapentin and gabapentin enacarbil. Eur J Clin Pharmacol 2013;69:180917. 
78. Zhang L, Rainka M, Freeman R, et al. A randomized, double-blind, placebo-controlled trial to assess the efficacy and safety of gabapentin enacarbil in subjects with neuropathic pain associated with postherpetic neuralgia (PXN110748). J Pain 2013;14:590-603.

79. Patsalos PN. Drug interactions with the newer antiepileptic drugs (AEDs)--part 1: pharmacokinetic and pharmacodynamic interactions between AEDs. Clin Pharmacokinet 2013;52:927-66.

80. Patsalos PN. Drug interactions with the newer antiepileptic drugs (AEDs)--Part 2: pharmacokinetic and pharmacodynamic interactions between AEDs and drugs used to treat non-epilepsy disorders. Clin Pharmacokinet 2013;52:1045-61.

81. Moore RA, Wiffen PJ, Derry S, et al. Gabapentin for chronic neuropathic pain and fibromyalgia in adults. Cochrane Database Syst Rev 2014;4:CD007938.

82. Yang M, Qian C, Liu Y. Suboptimal Treatment of Diabetic Peripheral Neuropathic Pain in the United States. Pain Med 2015;16:2075-83.

83. Rudroju N, Bansal D, Talakokkula ST, et al. Comparative efficacy and safety of six antidepressants and anticonvulsants in painful diabetic neuropathy: a network meta-analysis. Pain Physician 2013;16:E705-14.

- A network meta-analysis comparing efficacy and safety of different antiepileptics and antidepressants in the treatment of painful diabetic neuropathy.

84. Tassone DM, Boyce E, Guyer J, Nuzum D. Pregabalin: a novel gamma-aminobutyric acid analogue in the treatment of neuropathic pain, partial-onset seizures, and anxiety disorders. Clin Ther 2007;29:26-48.

85. Mico JA, Prieto R. Elucidating the mechanism of action of pregabalin: alpha(2)delta as a therapeutic target in anxiety. CNS Drugs 2012;26:637-48.

86. Froestl W. An historical perspective on GABAergic drugs. Future Med Chem 2011;3:16375.

87. Tjandrawinata RR, Setiawati E, Putri RS, et al. Pharmacokinetic equivalence study of two formulations of the anticonvulsant pregabalin. Clin Pharmacol 2015;7:69-75.

88. Schulze-Bonhage A. Pharmacokinetic and pharmacodynamic profile of pregabalin and its role in the treatment of epilepsy. Expert Opin Drug Metab Toxicol 2013;9:105-15.

89. Kanbayashi Y, Onishi K, Hosokawa T. Factors predicting adverse events associated with pregabalin administered for neuropathic pain relief. Pain Res Manag 2014;19:e164-7.

90. Hall GC, Morant SV, Carroll D, et al. An observational descriptive study of the epidemiology and treatment of neuropathic pain in a UK general population. BMC Fam Pract 2013;14:28.

91. Purwata TE. High TNF-alpha plasma levels and macrophages iNOS and TNF-alpha expression as risk factors for painful diabetic neuropathy. J Pain Res 2011;4:169-75.

92. Mikaili P, Moloudizargari M, Aghajanshakeri S. Treatment with topical nitroglycerine may promote the healing process of diabetic foot ulcers. Med Hypotheses 2014;83:172-4.

93. Huang LY, Tsui DY, Williams CM, et al. The Furoxan Nitric Oxide Donor, PRG150, Evokes Dose-Dependent Analgesia in a Rat Model of Painful Diabetic Neuropathy (PDN). Clin Exp Pharmacol Physiol 2015.

94. Motawi TK, Rizk SM, Ibrahim IA, El-Emady YF. Alterations in circulating angiogenic and anti-angiogenic factors in type 2 diabetic patients with neuropathy. Cell Biochem Funct 2014;32:155-63.

95. Varani K, Vincenzi F, Targa M, et al. Repeated Dosing with NCX1404, a Nitric OxideDonating Pregabalin, Re-establishes Normal Nociceptive Responses in Mice with Streptozotocin-Induced Painful Diabetic Neuropathy. J Pharmacol Exp Ther 2016;357:240-7. 96. Sayin R, Aslan M, Kucukoglu ME, et al. Serum prolidase enzyme activity and oxidative stress levels in patients with diabetic neuropathy. Endocrine 2014;47:146-51. 
97. Agrawal RP, Jain S, Goyal S, et al. A Clinical Trial of Nitrosense patch for the treatment of patients with painful diabetic neuropathy. J Assoc Physicians India 2014;62:385-90.

98. Liu Y, Jann M, Vandenberg C, et al. Development of an enantioselective assay for simultaneous separation of venlafaxine and O-desmethylvenlafaxine by micellar electrokinetic chromatography-tandem mass spectrometry: Application to the analysis of drug-drug interaction. J Chromatogr A 2015;1420:119-28.

99. Bray N. Analgesia: anti-itch and anti-ouch antibody. Nat Rev Drug Discov 2014;13:574.

100. Orestes P, Osuru HP, McIntire WE, et al. Reversal of neuropathic pain in diabetes by targeting glycosylation of $\mathrm{Ca}(\mathrm{V}) 3.2$ T-type calcium channels. Diabetes 2013;62:3828-38.

101. Dina OA, Hucho T, Yeh J, et al. Primary afferent second messenger cascades interact with specific integrin subunits in producing inflammatory hyperalgesia. Pain 2005;115:191203.

102. Dina OA, Parada CA, Yeh J, et al. Integrin signaling in inflammatory and neuropathic pain in the rat. Eur J Neurosci 2004;19:634-42.

103. Ferrari LF, Levine JD. Plasma membrane mechanisms in a preclinical rat model of chronic pain. J Pain 2015;16:60-6.

104. Schnitzer TJ, Marks JA. A systematic review of the efficacy and general safety of antibodies to NGF in the treatment of OA of the hip or knee. Osteoarthritis Cartilage 2015;23 Suppl 1:S8-17.

105. Hochberg MC. Serious joint-related adverse events in randomized controlled trials of anti-nerve growth factor monoclonal antibodies. Osteoarthritis Cartilage 2015;23 Suppl $1: \mathrm{S} 18-21$.

106. Wang H, Romano G, Frustaci ME, et al. Fulranumab for treatment of diabetic peripheral neuropathic pain: A randomized controlled trial. Neurology 2014;83:628-37.

107. Bramson C, Herrmann DN, Carey W, et al. Exploring the role of tanezumab as a novel treatment for the relief of neuropathic pain. Pain Med 2015;16:1163-76.

108. Brederson JD, Strakhova M, Mills C, et al. A monoclonal antibody against the receptor for advanced glycation end products attenuates inflammatory and neuropathic pain in the mouse. Eur J Pain 2015.

109. Yao CY, Weng ZL, Zhang JC, et al. Interleukin-17A Acts to Maintain Neuropathic Pain Through Activation of CaMKII/CREB Signaling in Spinal Neurons. Mol Neurobiol 2015.

110. Zhang FF, Morioka N, Harano S, et al. Perineural expression of high-mobility group box-1 contributes to long-lasting mechanical hypersensitivity via matrix metalloproteinase- 9 upregulation in mice with painful peripheral neuropathy. J Neurochem 2015.

111. Lakhan SE, Velasco DN, Tepper D. Botulinum Toxin-A for Painful Diabetic Neuropathy: A Meta-Analysis. Pain Med 2015;16:1773-80.

112. Jordt SE, Ehrlich BE. TRP channels in disease. Subcell Biochem 2007;45:253-71.

113. Payrits M, Saghy E, Matyus P, et al. A novel 3-(4,5-diphenyl-1,3-oxazol-2-yl)propanal oxime compound is a potent Transient Receptor Potential Ankyrin 1 and Vanilloid 1 (TRPA1 and V1) receptor antagonist. Neuroscience 2016;324:151-62.

114. Burness CB, McCormack PL. Capsaicin 8 \% Patch: A Review in Peripheral Neuropathic Pain. Drugs 2016;76:123-34.

115. Othman AA, Nothaft W, Awni WM, Dutta S. Pharmacokinetics of the TRPV1 antagonist ABT-102 in healthy human volunteers: population analysis of data from 3 phase 1 trials. J Clin Pharmacol 2012;52:1028-41.

116. Manitpisitkul P, Mayorga A, Shalayda K, et al. Safety, Tolerability and Pharmacokinetic and Pharmacodynamic Learnings from a Double-Blind, Randomized, Placebo-Controlled, Sequential Group First-in-Human Study of the TRPV1 Antagonist, JNJ-38893777, in Healthy Men. Clin Drug Investig 2015;35:353-63. 
117. Preti D, Saponaro G, Szallasi A. Transient receptor potential ankyrin 1 (TRPA1) antagonists. Pharm Pat Anal 2015;4:75-94.

118. de Vos CC, Meier K, Zaalberg PB, et al. Spinal cord stimulation in patients with painful diabetic neuropathy: a multicentre randomized clinical trial. Pain 2014;155:2426-31.

119. Smith TR. Duloxetine in diabetic neuropathy. Expert Opin Pharmacother 2006;7:215-23. 120. Ryan NM. A review on the efficacy and safety of gabapentin in the treatment of chronic cough. Expert Opin Pharmacother 2015;16:135-45.

121. Reinen J, Postma G, Tump C, et al. Application of a cocktail approach to screen cytochrome P450 BM3 libraries for metabolic activity and diversity. Anal Bioanal Chem 2016;408:1425-43.

122. Wellington K, Perry CM. Venlafaxine extended-release: a review of its use in the management of major depression. CNS Drugs 2001;15:643-69. 


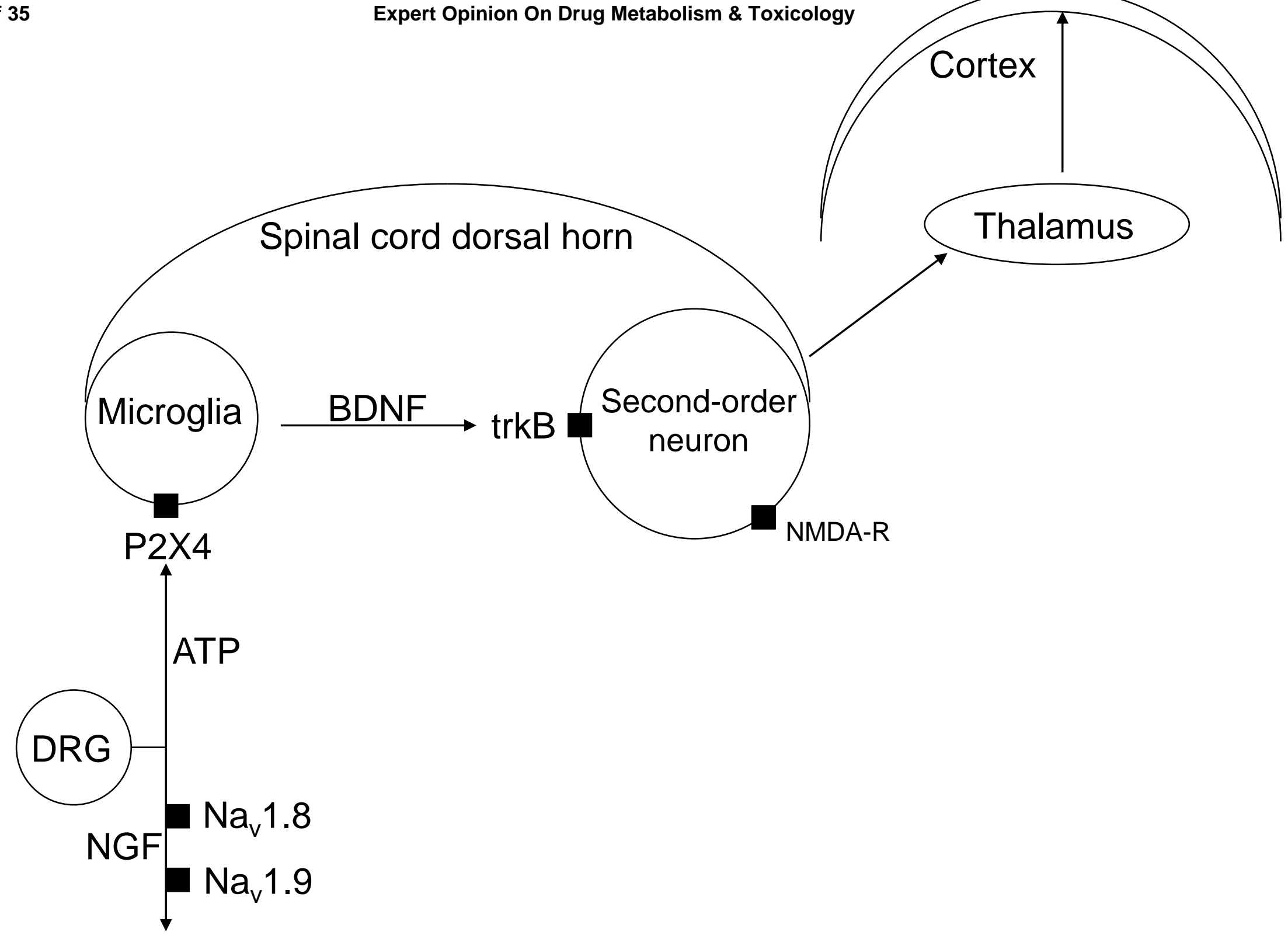


Figure 2. Chemical structures of the first-line drugs for PDN<smiles>CN(C)CCC=C1c2ccccc2CCc2ccccc21</smiles>

Amitriptyline (3-(10,11-Dihydro-5Hdibenzo[a, $]$ ] cycloheptene-5-ylidene)$N, N$-dimethylpropan-1-amine)<smiles>NCC1(CC(=O)O)CCCCC1</smiles>

Gabapentin

1-(Aminomethyl)cyclohexaneacetic acid<smiles>CNCC[C@H](Oc1cccc2ccccc12)c1cccs1</smiles>

Duloxetine

(+)-(S)-N-Methyl-3-(naphthalen-1-yloxy)3-(thiophen-2-yl)propan-1-amine<smiles>COc1ccc(C(CN(C)C)C2(O)CCCC2)cc1</smiles>

Venlafaxine

(RS)-1-[2-dimethylamino-1-(4methoxyphenyl)-ethyl]cyclohexanol 
Table 1. Pharmacokinetic and pharmacodynamic properties of the first-line drugs for the treatment of PDN

\begin{tabular}{|c|c|c|c|c|c|c|c|c|c|c|}
\hline Drugs & $\mathrm{C}_{\max }$ & $\mathbf{T}_{\max }$ & AUC & $T_{1 / 2}$ & $\begin{array}{l}\text { Bioavaila } \\
\text { bility }\end{array}$ & $\begin{array}{l}\text { Protei } \\
\text { n } \\
\text { bindin } \\
\text { g }\end{array}$ & $\begin{array}{l}\text { Volume } \\
\text { of } \\
\text { distribut } \\
\text { ion }\end{array}$ & $\begin{array}{l}\text { Metaboli } \\
\text { sm }\end{array}$ & Excretion & References \\
\hline \multicolumn{11}{|l|}{ Antidepressants } \\
\hline $\begin{array}{l}\text { Amitriptyline } \\
\text { (75 mg tablet) }\end{array}$ & $\begin{array}{l}15.3 \\
\mathrm{ng} / \mathrm{L}\end{array}$ & $\begin{array}{l}25.7 \\
h\end{array}$ & $\begin{array}{l}593 \\
\mathrm{ng} / \mathrm{mL} x \\
\mathrm{~h}\end{array}$ & $20.4 \mathrm{~h}$ & $30-60 \%$ & $96 \%$ & NA & $\begin{array}{l}\text { CYP2C1 } \\
9 \\
\text { CYP2D6 }\end{array}$ & $\begin{array}{l}\text { urine } \\
(30-50 \%) \\
\text { faeces } \\
\text { (NA) }\end{array}$ & {$[39,43]$} \\
\hline $\begin{array}{l}\text { Duloxetine } \\
\text { (60 mg tablet) }\end{array}$ & $\begin{array}{l}39- \\
40.1 \\
\text { ng/L }\end{array}$ & $6 \mathrm{~h}$ & $\begin{array}{l}584-591 \\
\text { ng x } \\
\mathrm{h} / \mathrm{mL}\end{array}$ & $10.2 \mathrm{~h}$ & $50 \%$ & $>90 \%$ & $1640 \mathrm{~L}$ & $\begin{array}{l}\text { CYP1A2 } \\
\text { CYP2D6 }\end{array}$ & $\begin{array}{l}\text { urine } \\
(70 \%) \\
\text { faeces } \\
(20 \%)\end{array}$ & {$[50,53,58]$} \\
\hline $\begin{array}{l}\text { Venlafaxine XR } \\
\text { (150 mg tablet) }\end{array}$ & $\begin{array}{l}150.0 \\
\mathrm{ug} / \mathrm{L}\end{array}$ & $5.5 \mathrm{~h}$ & $\begin{array}{l}1877 \\
\mathrm{ug} / \mathrm{L} \times \mathrm{h}\end{array}$ & $5.0 \mathrm{~h}$ & NA & $27 \%$ & NA & $\begin{array}{l}\text { CYP2D6 } \\
\text { CYP3A3 } \\
14\end{array}$ & $\begin{array}{l}\text { urine } \\
(87 \%) \\
\text { faeces } \\
\text { (NA) }\end{array}$ & [65] \\
\hline \multicolumn{11}{|l|}{ Antiepileptics } \\
\hline $\begin{array}{l}\text { Gabapentin } \\
\text { (600 mg tablet) }\end{array}$ & $\begin{array}{l}8.5 \\
\mathrm{mg} / \mathrm{L}\end{array}$ & $2.0 \mathrm{~h}$ & $\begin{array}{l}53 \mathrm{mg} / \mathrm{L} \\
\mathrm{x} \mathrm{h}\end{array}$ & $6.0 \mathrm{~h}$ & $\begin{array}{l}60 \% \\
(900 \\
m g / \text { day }) \\
27 \% \\
(4800\end{array}$ & $<3 \%$ & $\begin{array}{l}58 \mathrm{~L} \\
(150 \mathrm{mg} \\
\text { iv.) }\end{array}$ & nil & $\begin{array}{l}\text { urine } \\
\text { (NA) } \\
\text { faeces } \\
\text { (NA) }\end{array}$ & {$[76,79,83]$} \\
\hline
\end{tabular}




\begin{tabular}{|c|c|c|c|c|c|c|c|c|c|c|}
\hline & & & & & mg/day) & & & & & \\
\hline $\begin{array}{l}\text { Pregabalin } \\
\text { (150 mg capsule) }\end{array}$ & $\begin{array}{l}4.0 \\
\mathrm{ng} / \mathrm{L}\end{array}$ & $1 \mathrm{~h}$ & $\begin{array}{l}28 \mathrm{ug} / \mathrm{mL} \\
\mathrm{x} \mathrm{h}\end{array}$ & $5.7 \mathrm{~h}$ & $90 \%$ & absent & $0.5 \mathrm{~L} / \mathrm{kg}$ & nil & $\begin{array}{l}\text { urine } \\
(90 \%) \\
\text { faeces } \\
\text { (NA) }\end{array}$ & {$[87,88]$} \\
\hline
\end{tabular}

Abbreviations: AUC: the area under the concentration vs. time curve, $\mathrm{C}_{\max }$ : the maximum plasma concentration, h: hours, iv: intravenously, $\mathrm{L}$ : litre, NA: not available, PDN: painful diabetic neuropathy, Ref.: references, $\mathrm{T}_{\max }$ : the time to $\mathrm{C}_{\max }, \mathrm{T}_{1 / 2}$ : the plasma elimination half-life, XR: extended release 
Table 2. Recommended daily doses and adverse events of the first-line drugs for the treatment of PDN

\begin{tabular}{|l|l|l|l|}
\hline Drugs & $\begin{array}{l}\text { Recommended } \\
\text { daily dose (mg) }\end{array}$ & NNT & \multicolumn{2}{l|}{ Adverse events } \\
\hline Antidepressants & \multicolumn{2}{|c|}{} \\
\hline Amitriptyline & $25-100 \mathrm{mg}$ & 1.3 & $\begin{array}{l}\text { dry mouth, fatigue, somnolence, } \\
\text { weight gain, dizziness }\end{array}$ \\
\hline Duloxetine & $60-120 \mathrm{mg}$ & 6.0 & $\begin{array}{l}\text { nausea, dry mouth, headache, } \\
\text { dizziness, fatigue, somnolence, } \\
\text { constipation }\end{array}$ \\
\hline $\begin{array}{l}\text { Venlafaxine } \\
\text { Venlafaxine XR }\end{array}$ & $150-225 \mathrm{mg}$ & 3.1 & nausea, somnolence, hypertension \\
\hline Antiepileptics & & \multicolumn{3}{|l|}{} \\
\hline $\begin{array}{l}\text { Gabapentin } \\
\text { Gabapentin XR } \\
\text { Gabapentin } \\
\text { enacarbil }\end{array}$ & $1200-3600 \mathrm{mg}$ & 5.9 & $\begin{array}{l}\text { dizziness, somnolence, peripheral } \\
\text { oedema, gait disturbance, sedation, } \\
\text { weight gain }\end{array}$ \\
\hline Pregabalin & $300-600 \mathrm{mg}$ & 5.0 & $\begin{array}{l}\text { sedation, somnolence, dizziness, } \\
\text { headache, peripheral oedema, weight } \\
\text { gain }\end{array}$ \\
\hline
\end{tabular}

Abbreviations: NNT: number needed to treat; PDN: painful diabetic neuropathy; XR: extended release

(Ref.: $[3,4,7,34,46,53,63,64,81,84])$ 
PUBLISHING AGREEMENT

This is an agreement under which you, the author, assign copyright in your article to Informa UK Limited registered 1WG (hereinafter "T supplemental material hosted by us, as the Version of Record (VoR) in the Journal for the full period of copyrigh
the throughout the world, in all forms and all media, subject to the Terms \& Conditions below.

Please read this agreement carefully, complete it, and return a copy to us by email, fax, or hard copy immediately, to avoid any delay in the publication of your article

Postal address: Taylor \& Francis Journals Production, 4 Park Square, Milton Park, Abingdon OX14 4RN, UK Fax: +44 (0) 2070176336 Email: T\&Fproduction@tandf.co.uk

ARTICLE TITLE: ('Article') ALLEVIATION OF PAIIV IN PAMEUL DIABETIC NEUROPATIE'

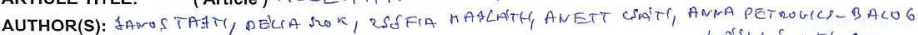
JOURNAL TITLE: Expert Opinion on Drug Metabolism \& Toxicology ('Journal') LASLL O US'CSE Please complete and sign below.

Please tick either box A or box B, BUT NOT BOTH

A A l own copyright, and I am assigning copyright in my article to Taylor \& Francis. In the case of a multi-authore article, I confirm that I am authorized by my co-authors to make this assignment as their agent on their behal The co-authors have agreed the priority of the assertion of copyright and the order of names in the publication

of the article.

Commercial servant or an employee of a Government, Government Agency, International Organization, or recognizes Taylor \& Francis as the sole licensee for the publication of the final, definitive, and citable Version of Record (VoR). In the case of a multi-authored article, I confirm that I am authorized by my co-authors to enter into this licence as their agent on their behalf. The co-authors have agreed the priority of the assertion of copyright
and the order of names in the publication of the article.

If you havc ticked B, please indicate which of the statements below apply to you (and your co-authors):

口 I I am an employee of the UK, Canadian, Australian, or another Commonwealth Realm Government, and the

Crown retains and asserts copyright.
Iam a US Government (including NIH) employee and there is no copyright to transfe

I am a contractor of the US Government (includes NIH contractors) under contract number

I am an employee of the European Commission and copyright is asserted and retained by the European

I am an employee of the World Bank and copyright is asserted and retained by that entity.

I am an employee of the Food \& Agricultural Organization and copyright is asscrted and retained by that

I am an employee of a Government, Agency, or International Organization and copyright is retained by that

I am employed and the copyright belongs to my employer (or is a 'work made for hire' under US law). Name of

ASSIGNMENT OF COPYRIGHT

I hereby assign Taylor \& Francis with full titlo guarantoc all rights of copyright and related publishing rights in my article, in all forms and all media (whether known at this time or developed at any time in the future) throughout the world, in all languages, where our rights include but are not limited to the right to translate, create adaptations, extracts, or derivative works and to sublicense such rights, for the full term of copyright (including all renewals and extensions of that term) to take effect if and when the article is accepted for publication.

I confirm that I have read and accept the full Terms \& Conditions below including my author warranties, and have read and agree to comply with the Journal's policies on peer review and publishing ethics.

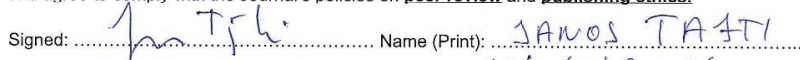

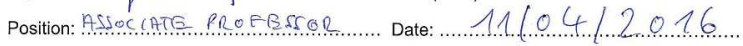

THIS FORM IS A LEGALLY BINDING DOCUMENT. WE RECOMMEND THAT YOU RETAIN A COPY OF IT AND CONSULT A LEGAL ADVISOR IF YOU HAVE ANY QUESTIONS.

$209 \times 298 \mathrm{~mm}(300 \times 300$ DPI $)$ 
ASSIGNMENT OF COPYRIGHT: TERMS \& CONDITIONS DEFINITION

1. Your artide is defined as comprising (a) your Acceptod Manuscript (AM) in its
final form: (b) the final, dofinitive, and citable Version of Record (VoR) inculuding

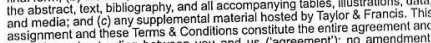

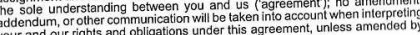
your and our rights and cbligations under
a written document signed by both of us.

TAYLOR \& FRANCIS' RESPONSIBILITIES

2. If deemed acceptable by the Editors of the Journal, we shall prepare eanu publish

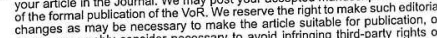

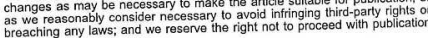

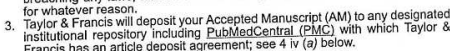

RIGHTS RETAINEU BY YOU AS AUTHOR

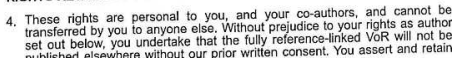
The following rights as author's:
The right to be identified as the author of your articie, whenever and

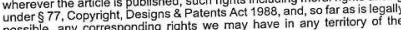
World dint to retain patent rights, trademark rights, or rights to any process,

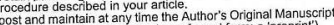

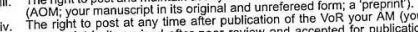

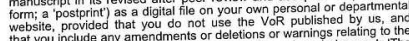

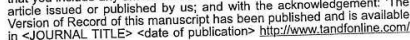
(a)

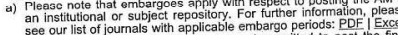

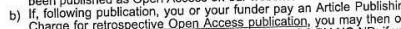

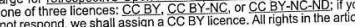

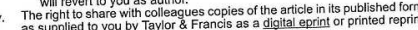

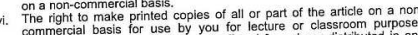

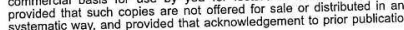

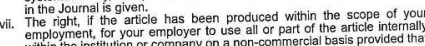

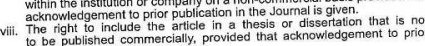

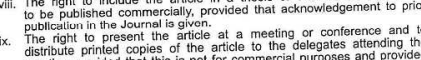

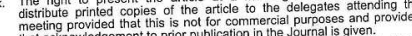

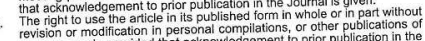

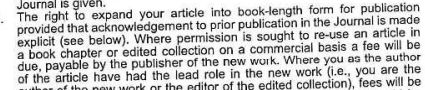
of the article have had the lead fole in the new work (i.e, you are the
at thor of the new work or the editior of the editied colloction, tees will be Acknowledgement: This \&chapter or books is derived in part

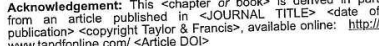

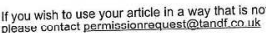

WARRANTIES MADE BY YOU AS AUTHOR

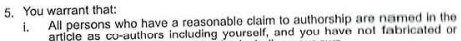

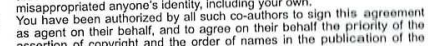

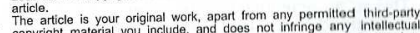

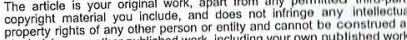

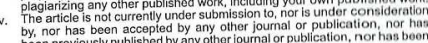

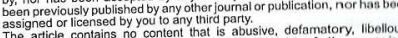

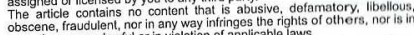

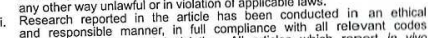
of
of experimentation and legistation. Al articles which report in vivo
experments or dinical trials on humans or animals must include a writion

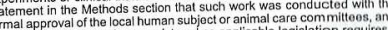

vi.

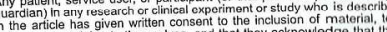
or image, pertaining to themselves, and that they acknowledge that the
annot be identified via the artide and that you have anonymized the

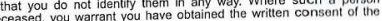

vili. You 作

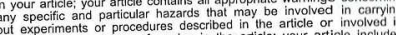

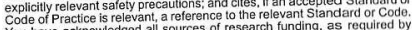

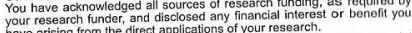

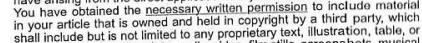

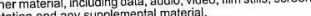

xi. You have read and complied with our policy on publisting etthics.

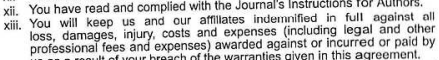

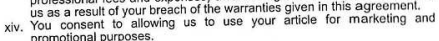
GOVERNING LAW

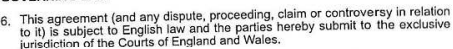

$209 \times 298 \mathrm{~mm}(300 \times 300$ DPI $)$

URL: http://mc.manuscriptcentral.com/eomt Email: David.Owusu@informa.com 